\title{
MENGATASI GANGGUAN PERKEMBANGAN BAHASA (DELAY ON READING) PADA ANAK SD KELAS RENDAH MELALUI PENDEKATAN PENGALAMAN BAHASA DAN METODE FONIK
}

\author{
Ryan Dwi Puspita, M.Pd \\ STKIP Sebelas April Sumedang \\ ryan.puspita@gmail.com
}

\begin{abstract}
Problems faced by children are usually associated with a disruption in the child's development. If not addressed, it will continue in the disruption next development phase is the development phase of school children. (Sri Maryati Deliana, et al, $p$. 1). One of them is a developmental disorder of language. Language serves as a communication tool and an important tool in the child's life. Through language, the child can interact, share experiences, and can improve the intellectual, namely in order to develop the knowledge and language skills. For children it is a period of development that must be nurtured and developed so that they can take advantage of language skills to the fullest. Without the guidance and direction feared their language development is not as expected by the parents at home and by teachers at school. (Dr. Enny Zubaidah, M. Pd., P. 1). Language delays are common disorders in early childhood or in the lower grade elementary school children. Language disorders such as this will hinder the social development of children. In this paper the child language disorders focused on the problem of type receptive language disorder. Examples of receptive language disorders in this case is the delay reading, children recognize letters but when united in one word the child can not memaknainya.Seperti other examples. As another example, a child who just saw the house, can not say that it is a home for disturbed memory warehouse. Also the ability to deliver the order (the ability to recognize or reproduce symbols in a sequence as presented) disturbed. For example, after introduced the symbol numbers 1 to 10 in a row, the child can not be mentioned in the order.
\end{abstract}

Keywords: Language Development Disorders (Delay on Reading), Low Grade Elementary School Children, Language Experience Approach and phonic method.

\section{ABSTRAK}

Masalah yang dihadapi oleh anak-anak biasanya berkaitan dengan gangguan pada perkembangan anak. Bila tidak segera diatasi, gangguan itu akan berlanjut pada fase perkembangan berikutnya yaitu fase perkembangan anak sekolah. (Sri Maryati Deliana,dkk, hal. 1). Salah satunya yaitu gangguan perkembangan bahasa. Bahasa berfungsi sebagai salah satu alat komunikasi dan merupakan sarana penting dalam kehidupan anak. Melalui bahasa, anak dapat saling berhubungan, saling berbagi pengalaman, dan dapat meningkatkan intelektual, yakni dalam rangka pengembangan pengetahuan dan keterampilan bahasanya. Bagi anak hal tersebut merupakan masa perkembangan yang harus dibina dan dikembangkan agar mereka dapat memanfaatkan kemampuan bahasanya secara maksimal. Tanpa adanya bimbingan dan arahan dikhawatirkan perkembangan 


\section{Didaktik : J urnal Pendidikan Guru Sekolah Dasar, ISSN : 2477-5673 \\ Sekolah Tinggi dan IImu Pendidikan Subang \\ Volume I Nomor 1, Desember 2015}

bahasa mereka tidak sesuai yang diharapkan oleh orang tua di rumah maupun oleh pendidik di sekolah.( Dr. Enny Zubaidah, M. Pd., hal. 1). Gangguan keterlambatan berbahasa biasa terjadi pada anak usia dini atau pada anak SD kelas rendah. Gangguan berbahasa seperti ini akan menghambat perkembangan sosial anak. Dalam tulisan ini gangguan berbahasa anak difokuskan pada masalah gangguan bahasa tipe reseptif. Contoh gangguan berbahasa reseptif dalam hal ini adalah keterlambatan membaca, anak mengenal huruf-huruf tapi ketika disatukan dalam satu kata anak tidak bisa memaknainya.Seperti contoh lainnya. Contoh lainnya, anak yang baru melihat rumah, tidak dapat mengatakan bahwa itu adalah rumah karena gudang ingatannya terganggu. Juga kemampuan memberikan urutan (kemampuan untuk mengenal atau mereproduksi simbol secara berurutan seperti yang disajikan) terganggu. Misalnya setelah dikenalkan simbol angka 1 sampai 10 secara berurutan , anak tidak dapat menyebutkannya secara urut.

Kata Kunci : Gangguan Perkembangan Bahasa (Delay on Reading), Anak SD Kelas Rendah, Pendekatan Pengalaman Bahasa dan Metode Fonik.

\section{Latar Belakang Masalah}

Masalah yang dihadapi oleh anak-anak biasanya berkaitan dengan gangguan pada perkembangan anak. Bila tidak segera diatasi, gangguan itu akan berlanjut pada fase perkembangan berikutnya yaitu fase perkembangan anak sekolah. (Sri Maryati Deliana,dkk,hal. 1). Salah satunya yaitu gangguan perkembangan bahasa.

Bahasa berfungsi sebagai salah satu alat komunikasi dan merupakan sarana penting dalam kehidupan anak. Melalui bahasa, anak dapat saling berhubungan, saling berbagi pengalaman, dan dapat meningkatkan intelektual, yakni dalam rangka pengembangan pengetahuan dan keterampilan bahasanya. Bagi anak hal tersebut merupakan masa perkembangan yang harus dibina dan dikembangkan agar mereka dapat memanfaatkan kemampuan bahasanya secara maksimal. Tanpa adanya bimbingan dan arahan dikhawatirkan perkembangan bahasa mereka tidak sesuai yang diharapkan oleh orang tua di rumah maupun oleh pendidik di sekolah.( Dr. Enny Zubaidah, M. Pd., hal. 1). Gangguan keterlambatan berbahasa biasa terjadi pada anak usia dini atau pada anak SD kelas rendah.

Gangguan berbahasa seperti ini akan menghambat perkembangan sosial anak. Dalam tulisan ini gangguan berbahasa anak difokuskan pada masalah gangguan bahasa tipe reseptif. Contoh gangguan berbahasa reseptif dalam hal ini adalah keterlambatan membaca, anak mengenal huruf-huruf tapi ketika disatukan dalam satu kata anak tidak bisa memaknainya.Seperti contoh lainnya. Contoh lainnya, anak yang baru melihat rumah, tidak dapat mengatakan bahwa itu adalah rumah karena gudang ingatannya terganggu. Juga kemampuan memberikan urutan (kemampuan untuk mengenal atau mereproduksi simbol secara berurutan seperti yang disajikan) terganggu. Misalnya setelah 
dikenalkan simbol angka 1 sampai 10 secara berurutan, anak tidak dapat menyebutkannya secara urut.

Contoh diatas sesuai dengan pendapat Heleen Van Agt,2011,hlm.9 mengenai gangguan perkembangan bahasa reseptif yaitu "Language disorders may appear as difficulties in the receptive, expressive and/or communicationdomain. A receptive language disorder means that the child has difficulties with understandingspoken language. Children need to understand language before they can use language adequately.'Dari pendapat diatas bisa diuraikan bahwa anak yang mengalami gangguan bahasa reseptif akan kesulitan menerima dan memahami bahasa lisan. Dan dalam hal ini anak-anak perlu memahami bahasa sebelum mereka dapat menggunakan bahasa secara memadai.

Dalam makalah ini permasalahannya difokuskan pada gangguan perkembangan bahasa yaitu keterlambatan membaca. Karena permasalahan membaca bagi anak Sekolah Dasar kelas rendah terutama kelas 1 sampai sekarang masih menjadi topik yang hangat. Anak yang tidak sekolah ke Taman Kanak-kanak terlebih dahulu atau langsung masuk ke SD biasanya mengalami kesulitan dalam hal membaca karena belum memperoleh pembelajaran membaca dini atau kurangnya stimulasi dari lingkungan.

Gangguan perkembangan bahasa reseptif terutama keterlambatan membaca biasanya terjadi di Sekolah Dasar di daerahdaerah atau pedalaman. Tapi tidak menutup kemungkinan hal ini terjadi di Sekolah Dasar yang beruntung. Karena jika dilihat, perkembangan anak itu bervariasi, hal ini sesuai dengan basic principles of development, yaitu :

"Domains of childern's development-

psysical,social,emotional and cognitive-are closely related. Development in one domain influences and is influenced by development in other domains. Development

advances when children have opportunities to practice newly acquired skills, as well as when they experience a challenge just beyond the level of their present mastery." (Gestwicki, 2006, hlm.12).

Jika dikaitkan dengan keterlambatan membaca pada anak, maka dari uraian diatas dapat ditarik kesimpulan bahwa keterampilan membaca pada anak sangat dipengaruhi oleh aspek perkembangan yang lain dan anak harus diberi kesempatan mengembangkannya. Dalam makalah ini dibahas mengenai gangguan perkembangan bahasa reseptif yang difokuskan pada permasalahan keterlambatan membaca dan program yang harus dilaksanakan dalam mengembangkannya.

\section{Perumusan Masalah}

Keterlambatan

membaca merupakan gangguan belajar yang melibatkan penurunan yang signifikan dari akurasi membaca, kecepatan, atau pemahaman dan penurunan nilai tersebut mengganggu prestasi atau aktivitas kehidupan akademis. Anak yang mengalami keterlambatan membaca 
mempunyai tingkat kecerdasan dibawah standar yang diharapkan. Sebenarnya gangguan membaca ini disebut disleksia.Yaitu anak defisit dalam ejaan menulis serta membaca. (Ensyclopedia of Mental Disolders, hal.1).

Tetapi yang dibahas dalam makalah ini hanya sebatas keterlambatan membaca pada anak SD kelas rendah. Jadi belum merupakan gangguan membaca yang akan berdampak dalam jangka waktu yang panjang kalau seorang guru dan lingkungan mampu memberikan stimulus.Sekaligus metode atau pendekatan untuk mengatasinya.

Keterlambatan membaca pada anak sangat berpengaruh pada perkembangan aspek yang lainnya, terutama pada menulis dan pemahaman materi-materi pelajaran yang lainnya. Apalagi jika hari ini kita harus mengikuti kurikulum 2013. Anak yang mempunyai gangguan keterlambatan membaca pasti tidak akan bisa mengikuti pembelajaran yang guru berikan.Karena pada proses pembelajaran kurikulum 2013 ini, anak SD kelas 1 harus sudah mahir membaca dan menulis.

Ketika melihat fenomena dilapangan, penulis pernah observasi kebeberapa SD di pedalaman dan SD yang beruntung, ternyata di kelas 1 masih ada beberapa anak yang masih belum mahir membaca dan ada yang sama sekali belum mengenal huruf. Melihat permasalahan diatas penulis memfokuskan masalahnya pada mengatasi gangguan perkembangan berbahasa (delay on reading) pada anak SD kelas rendah melalui pendekatan pengalaman pribadi dan metode fonik.

Dari fokus masalah diatas dapat dirumuskan beberapa pertanyaan, yaitu :
A. Bagaimana pemerolehan
bahasa anak menurut teori behavioral?
B. Apa penyebab terjadinya gangguan perkembangan bahasa?
C. Bagaimana gambaran anak SD kelas rendah yang mengalami gangguan perkembangan bahasa (delay on reading)?
D. Bagaimana upaya pemecahan masalah untuk mengatasi gangguan perkembangan bahasa (delay on reading) pada anak SD kelas rendah melalui pendekatan pengalaman bahasa?
E. Bagaimana upaya pemecahan
masalah untuk mengatasi
gangguan perkembangan bahasa (delay on reading) pada anak SD kelas rendah melalui metode fonik?

\section{Tujuan Penulisan Masalah}

Tujuan penulisan makalah ini adalah untuk melakukan kajian tentang gangguan perkembangan bahasa dalam hal ini difokuskan pada keterlambatan membaca (delay on reading) anak SD kelas rendah dan cara mengatasinya melalui pendekatan pengalaman pribadi dan metode fonik.

Secara lebih rinci penulisan makalah ini dimaksudkan untuk :
A. Untuk
mengetahui pemerolehan bahasa anak
menurut teori behavioral.
B. Untuk mengetahui penyebab gangguan perkembangan bahasa.
C. Untuk mengetahui gambaran anak SD kelas rendah yang


mengalami gangguan

perkembangan bahasa (delay on reading).

D. Untuk mengetahui upaya pemecahan masalah dalam mengatasi gangguan perkembangan bahasa (delay on reading) pada anak SD kelas rendah melalui pendekatan pengalaman bahasa.

E. Untuk mengetahui upaya pemecahan masalah dalam mengatasi gangguan perkembangan bahasa (delay on reading)pada anak SD kelas rendah melalui metode fonik.

\section{Analisis dan Pembahasan}

\section{A. Pemerolehan bahasa anak menurut teori behavioral}

Teori behavior adalah teori yang lebih menekankan pada kebiasaan. Teori yang dikembangkan oleh B.F Skinner ini, berpandangan bahwa pemerolehan bahasa anak dikendalikan oleh lingkungan. Artinaya, rangsangan anak untukberbahasa yang dikendalikan oleh lingkungan itu merupakan wujud dari perilaku manusia (Gleason, 1998:381).

Menurut kaum Behavioris, anak-anak lahir dengan potensi belajar dan perilaku mereka dapat dibentuk dengan memanipulasi lingkungan. Dengan penguatan yang benar, kemampuan intelektual anak dapat dikembangkan.Teori yang dikemukakan oleh B.F Skinner ini lebih menekankan pada kebutuhan "pemeliharaan" perkembangan intelektual dengan memberikan stimulus pada anak dan menguatkan perilaku anak.

Diuraikan (Clark dan Clark, 1977; Dworetzky, 1990; Gleason,
1998) bahwaseorang bayi sebenarnya masih bersifat pasif, sehingga ia menerima stimulus dari lingkungannya dan kemampuan berkomunikasi melalui bahasa yang ditentukan oleh stimulus dan peniruan. Jadi, kemampuan bahasa anakditentukan oleh lamanya latihan dari stimulus yang diberikan, sehingga kemampuan bahasa anak tidak berlandaskan pada penguasaan kaidah, namun berdasarkan pada apa yang diperolehnya. Oleh karena itu, menurut Skinnerperlu adanya suatu latihan dan pengarahan. Maksudnya bahwa dalam belajarperlu adanya kondisi latihan bahkan perlu adanya "operan" yaitu suatu kondisiyang ada karena kebutuhan. Pengarahan juga dibutuhkan dalam upaya ini, agar tujuan tercapai.

Ada tiga macam pembelajarannya, yaitu (1) pengkondisian klasik (classicalconditioning) adalah yang berkaitan dengan stimulus dan respon, (2) pengkondisian operan (operan conditioning) adalah yang berkaitan dengankebiasaan melalui pemberian hadiah (reward atau reinforcement), dan (3)pembelajaran sosial (sosial learning) yaitu yang berkaitan dengan pengamatan dan peniruan seorang anak.Berdasarkan ketiga macam pembelajaran tersebut, dalam praktiknya guru hendaklah memberikan rangsangan kepada anak agar mau melakukan tindakan yang selalu menggunakan keterampilan bahasanya. Misalnya dengan menyediakan pajangan di dalam kelas, mungkin berupa majalah, menempel berbagai gambar yang menarik di dalam kelas, mengajak 
bicara kepada anak,memberi pertanyaan ringan kepada anakanak, dan sebagainya. Melalui upaya/rangsangan tersebut, anak diharapkan secara spontan berani mengungkapkan bahasanya secara lisan.

Jadi, diharapkan setelah guru memberi stimulus anak akan segera merespon. Hadiah memang menjadikan sebuah dilema klasik. Dikhawatirkan jika guru/orang tua tidak memberi hadiah, biasanya anak enggan melakukannya. Satu hal yang mungkin terjadi yaitu kondisi belajar sudah terbentuk, namun kondisi tersebut kembali seperti semula karena hadiah tidak diberikan lagi. Oleh karena itu, guru dan atau orang tua harus bijaksanan dalam mengatasi hal ini.

Jangan sampai anak mau melakukan sesuatu, termasuk dalam berbahasa karena dia ingin mendapatkan hadiah. Dalam prinsip peniruan, anak akan berbahasa sesuai dengan apa yang ia lihat dan dia dengar. Jika orang-orang yang berada di sekitar anak menggunakan bahasa yang benar secara kaidah, maka anak pun akan melakukan hal yang serupa. Namun jika tidak, maka anak pun akan berbahasa sesuai apa yang diperolehnya. Apa yang dikatakan Lightfoot (1982) dalam(Gleason, 1998: 378) dari salah satu faktor yang mempengaruhi perkembangan bahasa anak itu adalah benar, karena anak belum dapat membedakan penggunaan bahasa yang baik dan yang buruk. Jadi, sebagai guru dan atau orang tua, hendaklah berlaku bijaksana agar anak dapat mengembangkan kemampuan bahasanya secara proporsional.

\section{B. Penyebab gangguan bahasa \\ terjadinya perkembangan}

Penyebab terjadinya gangguan perkembangan bahasa bisa terjadi karena disfungsi minimal otak (DMO) dan kesulitan belajar. Dan merupakan dua hal yang satu sama lain saling berhubungan, meskipun Touwen (Semiawan, 2002:64)mengatakan bahwa tidak setiap ketidakmampuan belajar dan tingkah laku terkait dengan DMO, akan tetapi DMO akan berakibat pada kesulitan belajar pada anak. Istilah kesulitan belajar yang lebih spesifik ini adalah kesulitan belajar khusus (KBK).

Semiawan

(2002:

menguraikan ada tiga kelompok kemungkinan penyebab yang bisa menjadi perkiraan mengapa, bilamana dan bagaimana terjadi KBK sebagai akibat dari DMO.

(1). Sebab Prenatal

Faktor keturunan, meskipun secara jelas menampakan perannya terhadap DMO, namun terjadinya infeksi pada embrio bisa juga berakibat pada janinyang ada dalam kandungan.

(2). Sebab Perinatal

Proses kelahiran bayi yang mengalami terpluntirnya tali usus, bisamenjadikan kelainan infeksi tertentu pada otak dengan akibat pada DMO.

(3). Sebab Postnatal

Berbagai penyakit yang timbul pada anak setelah lahir, misalnya campak,batuk rejan dan penyakit lain bisa menjadi penyebab dari DMO dan berakibat pada KBK. 
Beberapa ciri DMO pada anak dan dampaknya terhadap $\mathrm{KBK}$, diuraikan

Semiawan (2002:64-65) berikut ini. (1). Hasil penelitian Cruickshank tahun 1972, (Semiawan, 2002) biasanya DMO terjadi pada anak laki-laki. Hal ini ditandai dengan ketidakmampuan bayimenetek. Makin besar anak, makin tidak memiliki kemampuan dalam koordinasi motorik. Jika sudah agak besar lagi anak suka bermain mobil mobilan dan sangat otoriter. Suka menganiaya binatang, suka mengamuk. Intelegensinya bervariasi dari bawah rata-rata sampai dengan superior.

(2). Ciri lain sehingga anak DMO memerlukan penanganan khusus, adalah: (a)

mudah beralih perhatiannya, (b) hiperaktif motoris atau sensoris, (c) implusif,(d) emosi labil, (e) integrasi motorik rendah, (f) penyeimbangan dalampersepsi ruang, bentuk, dan gerak dan waktu, (g) kekakuan bahasa, (h)disosiasi dan keterlibatan persepsi tentang latar belakang dan benda utama. (Zubaidah, Eny,hal.23).

C. Gambaran umum anak yang mengalami gangguan perkembangan bahasa (delay on reading).

Perkembangan bahasa anak ditempuh melalui cara yang sistematis dan berkembang bersama-sama dengan pertambahan usianya. Anak melewati tahap perkembangan yang sama, meskipun berbeda latar belakang kehidupannya, misalnya: sosial keluarga, kecerdasan, kesehatan, dorongan, hubungan dengan teman dan sebagainya, yang turut mempengaruhinya, hingga terjadi perbedaan (Hurllock, 1978). Menurut Lenneberg (1967) dalam Purwo (1997) dinyatakan bahwa perkembangan bahasa anak berjalan sesuai dengan jadwal biologisnya. Hal inilah yang digunakan sebagai dasar mengapa anak pada umur tertentu sudah dapat berbicara, sedangkan anak pada umur tertentu pula belum dapat berbicara. Jelaslah bahwa alasan tersebut mengarah pada perkembangan motorik dan bukan pada perkembangan usianya.

$$
\text { Akan tetapi dalam }
$$

perkembangannya, semua anak memiliki komponen pemerolehan bahasa yang sama, baik perkembangan fonologinya, sintaksisnya, semantiknya, maupun pragmatiknya. Hal ini tentunya dilihat dari segi perkembangan bahasa anak yang normal. Kesemua komponen tersebut dapat dilihat dari gejala dan tingkah laku anak (Jalongo, 1992:13). Berikut dibagankan komponen pemerolehan bahasa dan ciri tingkah laku anak yang dimaksud pada tabel 1.1 di bawah ini.

Tabel 1.1

Komponen Pemerolehan Bahasa Anak dan Ciri Tingkah Lakunya

\begin{tabular}{|c|c|}
\hline $\begin{array}{l}\text { KOMPONEN } \\
\text { BAHASA }\end{array}$ & $\begin{array}{l}\text { CIRI } \\
\text { TINGKAH } \\
\text { BAHASA } \\
\text { ANAK }\end{array}$ \\
\hline $\begin{array}{l}\text { 1. Fonologi } \\
\text { (sistem bunyi) }\end{array}$ & $\begin{array}{l}\text { Keutuhan } \\
\text { dalam } \\
\text { bersuara }\end{array}$ \\
\hline $\begin{array}{l}\text { 2. Sintaksis } \\
\text { (sistem } \\
\text { gramatikal) }\end{array}$ & $\begin{array}{l}\text { Memproduksi } \\
\text { suara }\end{array}$ \\
\hline $\begin{array}{l}\text { 3. Semantik } \\
\text { (sistem }\end{array}$ & $\begin{array}{l}\text { Keutuhan } \\
\text { dalam }\end{array}$ \\
\hline
\end{tabular}




\begin{tabular}{|c|c|c|}
\hline & makna) & $\begin{array}{l}\text { memberikan } \\
\text { makna }\end{array}$ \\
\hline & $\begin{array}{l}\text { Pragmatik } \\
\text { (sistem } \\
\text { interaksi } \\
\text { sosial) }\end{array}$ & $\begin{array}{l}\text { Penerapan } \\
\text { ucapan dalam } \\
\text { kehidupan } \\
\text { sosial secara } \\
\text { utuh. }\end{array}$ \\
\hline
\end{tabular}

Sumber: Levin G. (1983)

Psikologi Anak; Belmont CA: Wadsworth

Berdasarkan empat komponen pemerolehan bahasa anak tersebut, Hedberg (Kusumoputro, 1991: 13) menghubungkannya ke dalam tiga aspek bahasa yaitu aspek sosial, kognitif dan linguistik. Hubungan komponen bahasa dan ciri tingkah laku bahasa anak tersebut dapat dirangkum pada tabel 1.2 di bawah ini.

Tabel 1.2

Hubungan antara Komponen

Bahasa dan Aspek Bahasa

\begin{tabular}{|l|l|l|}
\hline Pragmatik & Penggunaan & Sosial \\
\hline Semantik & Isi & Kognitif \\
\hline Sintaksis & Bentuk & Linguistik \\
Morfologi & & \\
Fonologi & & \\
\hline
\end{tabular}

Sumber: Sidiarto Kusumoputro

(1991)

Afasia Gangguan Berbahasa Jakarta: Fakultas Kedokteran UI

Bahasa dan bicara merupakan ekspresi seseorang yang menunjukkan kemampuannya dalam mengungkapkan sesuatu. Hal tersebut diperoleh melalui proses belajar yang cukup unik karena bahasa dan berbicara tersebut digunakan sehari-hari melalui proses informal. Itulah yang disebut dengan pemerolehan bahasa.

Seseorang dapat dan mampu berbahasa dan berbicara tersebut bukan saja diperoleh secara menurun dari orang tuanya namun melalui proses belajar yang alami dan melalui konteks yang wajar. Menurut
Tarmansyah (1996:50-61) ada beberapa faktor yang mempengaruhi perkembangan bahasa dan bicara pada anak. Faktor tersebut adalah: (1) kondisi jasmani dan kemampuan motorik, (2) kesehatan umum, (3) kecerdasan, (4) sikap lingkungan, (5) faktor sosial ekonomi, (6) jenis kelamin, (7) kedwibahasaan, dan (8) neurologi.

Berbicara masalah gangguan berbahasa tidak dapat dipisahkan dengan peran otak dan produksi bahasa. Menurut Broca dalam (Gleason, 1998) , gangguan otak berpengaruh sekali dengan gangguan bahasa. Dalam makalah ini gangguan bahasa yang dibahas adalah tipe reseptif, yaitu kegagalan untuk mengembangkan pengertian bahasa (decoding) dan ekspresi vokal bahasa (encoding). Gangguan ini disebabkan oleh kekurangan yang terdapat dalam persepsi sensoris (pengenalan simbol-simbol), visual (gambar) atau auditorik (suara) atau integrasi keduanya yaitu menghubungkan atau memanipulasi simbol-simbol visual dan auditorik. (Deliana, dkk, hlm. 18).

Dalam makalah ini dibahas mengenai gangguan perkembangan bahasa reseptif yaitu keterlambatan membaca (delay on reading). Membaca adalah sebuah proses yang kompleks. Membaca mencakup kajian tentang bahasa, memori, pikiran, kecerdasan dan persepsi. Kemampuan untuk membaca sangat fundamental bagi kehidupan anak.Gangguan membaca pertama kali diakui pada akhir abad 19 yang dikenal dengan sebutan alexia perkembangan. Mulai tahun 1960-an, dikenal dengan disleksia.

Masalah-masalah pemrosesan fonologis dan dari situ pengidentifikasian kata, menjadi penghalang terbesar di dalam upaya 


\section{Didaktik : J urnal Pendidikan Guru Sekolah Dasar, ISSN : 2477-5673 \\ Sekolah Tinggi dan Ilmu Pendidikan Subang \\ Volume I Nomor 1, Desember 2015}

belajar membaca. (Grodzinksky, 2003;Pollastek\&Rayner,1989,hlm.40)

.Proses pertama yang harus diperhatikan adalah kesadaran fonologis. Proses ini mengacu kepada struktur bunyi dari bahasa ucapan. Biasanya memiliki kesadaran fonologis lewat tugas penghapusan fonem (phoneme-delection task). Misalnya anak-anak diminta mengatakan 'goat' tanpa fonem 't'. Tugas lain yang digunakan adalah menghitung fonem. Anak-anak ditanya seberapa banyak bunyi yang berbeda di dalam kata 'fish'.

Proses kedua yang harus diperhatikan adalah adalah pembacaan fonologis. Proses ini membaca kata-kata secara terisolasi. Guru kadang menyebut kemampuan ini 'pengkodean kata'. Untuk mengukur kemampuan ini, anak diminta membaca kata-kata yang terisolasi. Beberapa kata bisa cukup mudah, yang lainnya sulit.

Proses ketiga yang harus diperhatikan adalah pengodean fonologis di dalam memori yang sedang bekerja. Proses ini terlibat di dalam pengingatan rangkaianrangkaian fonem yang terkadang membingungkan. Contohnya, seorang anak bisa dinilai untuk seberapa baiknya dia mengingat rangkaian 't,b,z,v,g' versus 'o, $x, r, y, q$ '. Kebanyakan anak mengalami kesuliatan pada rangkaian pertama.

Proses keempat yang harus diperhatikan adalah pengaksesan kosakata. Proses ini mengacu kepada kemampuan seseorang mengeluarkan fonem-fonem dari memori jangka panjang. Contoh, jika anak melihat kata 'buah', apakan anak langsung mengenali kata itu sebagai 'buah' ataukah memerlukan waktu sebentar untuk mengeluarkan kata itu dari memori.

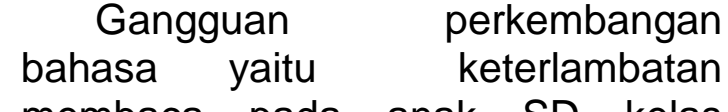
membaca pada anak SD kelas rendah yang terjadi adalah ketika anak bisa mengenali huruf-huruf tetapi ketika disatukan dalam satu kata tidak bisa membunyikannya, anak belum mengenal huruf sama sekali, anak bisa membaca tetapi tidak mengerti maknanya. Gangguan seperti ini masuk ke dalam kategori disleksia perkembangan (developmental dyslexia), yaitu kesulitan membaca yang dimulai sejak masa kanak-kanak. Umumnya, anak-anak disleksia ini mengalami kesulitan dalam mempelajari aturanaturan yang mengaitkan huruf dengan bunyi. (Sternberg,2008,hlm.323).

\section{Formulasi Upaya Pemecahan}

Pengembangan keterampilan membaca yang baik dan tepat perlu diketahui dan dikembangkan oleh guru SD. Maka diperlukan strategi pengembangan yang sesuai dengan karakteristik anak dan pengembangannya harus tetap berpijak pada kemampuan prakolastik yang lebih substansial. Seperti yang dikemukakan Bromley (1992:216) strategi yang digunakan harus menyediakan dengan tepat sesuai minat yang dibutuhkan anak, juga melibatkan anak dan situasi yang berbeda dalam kelompok kecil, kelompok besar atau secara individual.

Strategi yang digunakan dalam mengembangkan kemampuan membaca pada anak SD kelas rendah adalah dengan pendekatan pengalaman berbahasa. Pendekatan ini diberikan dengan menerapkan konsep DAP (Developmentally Aproppriate Practice). Pendekatan ini disesuaikan dengan karakteristik anak dengan menggunakan metode mengajar yang tepat untuk 


\section{Didaktik : J urnal Pendidikan Guru Sekolah Dasar, ISSN : 2477-5673 \\ Sekolah Tinggi dan Ilmu Pendidikan Subang \\ Volume I Nomor 1, Desember 2015}

mengembangkan kemampuan membaca serta melibatkan anak dalam kegiatan yang dapat memberikan berbagai pengalaman bagi anak. Selain itu, perlu juga memperhatikan motivasi dan minat anak sehingga kedua faktor itu berpengaruh besar dalam pengembangan keterampilan membaca.

(Dhieni,

Nurbiana,2008,hlm. 5.22).

Metode pengembangan yang tepat untuk mengatasi delay on reading atau keterlambatan membaca adalah :

\section{A. Pendekatan bahasa}

Dalam pendekatan ini guru menggunakan kata-kata anak sendiri untuk membantunya belajar membaca. Kata-kata itu dapat berupa penjelasan gambar atau suatu cerita pendek yanng dimasukkan dalam satu buku. Mula-mula anak mengatakan kepada guru apa yang harus ditulis. Setelah beberapa waktu anak-anak dapat menyalin tulisan guru dan akhirnya dapat menuliskan kata-kata mereka sendiri.

Banyak guru yang menggunakan metode ini sebagai suatu pendekatan pertama untuk membaca. Membaca kata-kata mereka sendiri membantu anak-anak memahami bahwa kata yang tertulis adalah untuk komunikasi makna. Jadi kekuatan dari pendekatan pengalaman bahasa yang utama adalah dapat membuat anak menggunakan pengalaman mereka sendiri.

Langkah-langkah yang harus dilakukan guru dalam pendekatan ini adalah:

(1). Mengidentifikasi anak

Mengenali anak yang memiliki gangguan keterlambatan membaca melalui tes membaca. (2). Mengetahui prasyarat membaca
Sebelum belajar membaca anak harus melalui tahapan prasyarat membaca. Anak yang memiliki gangguan keterlambatan membaca akan mempunyai hambatan dalan mengkode simbol. Oleh karena itu sebelum belajar membaca harus dipastikan dulu kemampuan kesadaran simbol anak (persepsi visual) yaitu visual spasial, visual diskriminasi, figure and ground dan visual memori.

(3). Merencanakan dan menyusun teknik penilaian

Penilaian disini adalah alat untuk mengetahui dan menggali daftar kosa kata dan kalimat berdasarkan pendekatan pengalaman bahasa. Ada dua penilaian yang disiapkan, yaitu :
a) Penilaian alamiah yaitu dilakukan dengan cara bercakap-cakap atau tanya jawab mengenai pengalaman sehari-hari.
b) Penilaian yang dikondisikan yaitu dengan cara guru menyiapkan gambar-gambar. Anak melihat gambar tersebut dan menceritakan kembali apa yang dilihat berdasarkan pengalaman bahasanya.

Setelah melakukan penilaian, selanjutnya guru menganalisis pola kosa kata dan kalimat yang dimiliki anak dan membagi pada pola-pola berikut, misalnya : kv$k v, k v-k v-k v, k v-k v-k, k-k v-k$ dst.

Keterangan :

$\mathrm{K}$ : konsonan

$\mathrm{V}$ : vokal

(4). Melakukan intervensi

Pada fase ini anak membaca kata-kata dan kalimat dari pola termudah dulu hingga yang tersulit. Dari hal tersebut guru bisa menilai kata-kata mana saja yang bisa anak baca secara 
konsisten dan kata-kata mana saja yang belum dapat dibaca. Selanjutnya dilakukan intervensi, yaitu anak membaca kata-kata yang belum bisa ia baca. Anak membaca kata-kata dan kalimat yang diperoleh dari penilaian yang tadi yaitu kata-kata dan kalimat berdasarkan pengalaman bahasa anak sendiri. Contoh pola yang dibuat, yaitu :

Saya Citra

Sa ya Cit ra

$S$ a y a C i t $r$ a

Sa ya Cit ra

Saya Citra

\section{B. Metode fonik}

Metode ini mengandalkan pada pelajaran alfabet yang diberikan terlebih dahulu kepada anak, mempelajari nama-nama huruf dan bunyinya. Setelah mempelajari bunyi huruf, anak mulai merangkum huruf-huruf tertentu untuk membentuk kata-kata.

$$
\text { B - a - k r } \quad r-a-k \quad k a-t a k
$$

Untuk memberikan latihan membaca kepada anak dalam keterampilan ini, buku cerita harus dipilih secara terencana, sehingga semua kata bersifat reguler dan dapat dibunyikan. Sangat sukar untuk menulis buku dengan katakata yang secara fonik bersifat reguler, yang menarik untuk dibaca anak. Contohnya :

Satu dua tiga

Si gendut naik kuda

Dalam metode ini anak benar-benar harus memusatkan pemikirannya akan pembunyian kata-kata, karena dalam metode ini anak harus membunyikan kata-kata tanpa harus mengetahui maknanya. Penggunaan metode ini mempunya prasyarat yaitu anak harus memahami benar dasar-dasar membaca dengan baik.

\section{Pihak-pihak yang terlibat dalam penanganan masalah}

Berdasarkan kenyataan dan pengalaman, ada beberapa pihak yang diikut- sertakan dalam menangani masalah gangguan keterlambatan berbahasa yaitu delay on reading ini. Karena penyebab dari satu masalah bukan bersifat tunggal. Setiap masalah harus dilihat dari berbagai aspek, seperti aspek biologis, psikis dan sosial.

Sesuai dengan aspek-aspek tersebut, maka pihak-pihak yang ikut berperan dalam menangani masalah ini adalah guru, orang tua anak, psikolog, psikiater, rekan guru, pihak yayasan yang mengelola SD tersebut, Depdikbud.

Kerjasama yang perlu yang perlu dibangun dalam menangani masalah ini terutama dari pihak guru dengan orang tua anak.Jadi harus ada kerjasama dalam membimbing anak belajar membaca misalnya setelah anak belajar membaca di sekolah, hal ini harus ditindak lanjuti oleh orang tua di rumah. Dan orang tua anak harus meluangkan waktunya untuk membimbing anak.

6. Kesimpulan dan Rekomendasi

Kesimpulan dan rekomendasi yang bisa ditarik dari kajian makalah ini adalah sebagai berikut :

A. Kesimpulan

(1) $\mathrm{Di}$ beberapa SD di pedalaman dan SD yang beruntung, ternyata di kelas 1 masih ada beberapa anak yang masih belum mahir membaca dan ada yang sama sekali belum mengenal huruf. Melihat permasalahan diatas penulis memfokuskan masalahnya pada mengatasi gangguan perkembangan berbahasa (delay on reading) pada anak SD kelas rendah 
melalui pendekatan pengalaman pribadi dan metode fonik.

(2) Faktor penyebabnya adalah kurangnya stimulasi lingkungan baik guru ataupun orangtua dan bisa dari faktor biologis dan psikis anak itu sendiri.

(3) Solusi yang harus dilakukan guru di sekolah adalah menyiapkan metode belajar membaca yang tepat untuk anak yang mengalami gangguan keterlambatan membaca, dalam hal ini adalah pendekatan pengalaman bahasa dan metode fonik. Yang harus orang tua lakukan adalah harus meluangkan waktunya untuk membimbing anak dan menciptakan suasana belajar yang menyenangkan di rumah.

(4) Kalau tidak ada penanganan yang serius dari pihak-pihak yang terkait maka gangguan keterlambatan membaca ini akan terjadi dalam waktu yang sangat panjang, dengan kondisi seperti ini anak tidak bisa mengikuti pembelajaran pada tahap selanjutnya.

B. Rekomendasi

(1) Guru

Seorang guru harus mampu memilih metode pembelajaran yang tepat untuk anak dan hal ini disesuikan situasi dan kondisi anak.

(2) Orang tua

Para orang tua harus bisa meluangkan waktu untuk membimbing anak dan harus bisa kerjasama dengan pihak sekolah dalam hal pembelajaran

dan pendidikan.

(3) Kepala sekolah

Kepala sekolah harus memfasilitasi terjadinya kegiatan belajar mengajar yang aktif dan menyenangkan. Dalam hal ini berarti harus menciptakan lingkungan yang baik untuk belajar.

\section{DAFTAR PUSTAKA}

Andriana, Elga. Problema Anak Usia Dini Berbasis Gender. Yogyakarta : Penerbit Kanisius.

Block, Frances K.; Amie Amiot, Cheryl Deconde Johnson; Gina E. Nimmo; Peggy G. Von Almen; Deborah W. White; and Sara Hodge Zeno (1993), "Definitions of Communication Disorders and Variations", $A d$ Hoc Committee on Service Delivery in the Schools, ASHA, doi:10.1044/policy.RP199300208, retrieved 2010-08-07

Brady, MC; Kelly, H; Godwin, J; Enderby, P (May 16, 2012). "Speech and language therapy for aphasia following stroke.". The Cochrane database of systematic reviews5: CD000425. doi:10.1002/14651858.CD000 425.pub3. PMID 22592672.

Bredekamp, Sue. (1987). Developmentally Appropriate Practice in Early Childhood Programs Serving Children from Birth Through Age 8. Washington,DC: National Association for the Education of Young Children.

Breit-Smith, Allison. Dkk. Language, Speech \& Hearing Services in Schools (Online). 
Washington: Jan 1, 2010. Vol. 41, Iss. 1; pg. 96, 12 pgs

Brice, A. (2001). Children with communication disorders (ERIC Digest \#E617). Arlington, VA: ERIC Clearinghouse on Disabilities and Gifted Education. (Available online at: http://ericec.org/digests/e617.h $\underline{\mathrm{tml}})$.

Charkins, H. (1996). Children with facial differences: A parents' guide. Bethesda, MD: Woodbine House. Web: www.woodbinehouse.com)

Clark, Eve V. Dan Herbert H. Clark. (1977). Psychology and Language. New York : Harcourt Brace Jovanovich.

Crain, William. (2011). Theories of Development Concepts and Application. USA: Pearson.

DeBonis DA, Moncrieff D (February 2008). "Auditory processing disorders: an update for speech-language

pathologists". Am J Speech Lang Pathol17 (1): 4-18. doi:10.1044/1058-

0360(2008/002).

PMID 18230810.

Deliana, Sri M.,dkk. Permasalah anak TK. Jakarta : Depdikbud

Dehart, Ganie B.,dkk. (2004). Child Development its Nature and Course. Boston : Mc Graw Hill.

DePorter, Bobbi dkk. (1999). Quantum Learning. Bandung : Kaifa.

Desmond DW (2004). The neuropsychology of vascular cognitive impairment:is there a specific cognitive deficit?.Journal of Neurological Sciences 226: 3-7.
Dhieni, Nurbiana. (.2008).Metode Pengembangan Bahasa. Jakarta : UT

$\mathrm{Dr}$ Nancy Dickey, taken from $\mathrm{Dr}$ Nancy Dickey's Column http://www.medem.com/msphs /msphs_drdickeycolumns_deta il.

Catts, H.W., Fey, M.D., Zhang, X. \& Tomblin, J.B. "Language basis of reading disabilities: Evidence from a longitudinal investigation," Scientific Studies of Reading; 1999; 3:331-361.

Frank M.Cirrin and Ronald B. Gillam. Language Intervention Practices for School-Age Children With Spoken Language Disorders: $A$ Systematic Review. Language, Speech, and Hearing Services in Schools, January 2008, Vol. 39 , S110-S137. doi:10.1044/01611461(2008/012)History: Received February 8, 2007; Revised May 30, 2007; Accepted August 13, 2007

Gail T. Gilon,Language, Speech, and Hearing Services in Schools, The Efficacy of Phonological Awareness Intervention for Children With Spoken Language Impairment April 2000, Vol. 31, 126-141. doi:10.1044/01611461.3102.126 History: Received September 22, 1999; Accepted December 17, 1999

Gestwicki, Carol. (2007). Developmentally Appropriate Practice Curriculum and Development in early Education. Australia : Thomson.

Gunarti, Winda,dkk.(2008). Metode Pengembangan dan Kemampuan Dasar AUD. Jakarta: UT. 
Grossman M (2002) Frontotemporal dementia: a review.Journal of International

Neuropsychological Society 8: 566-583.

http://www.asha.org/certification/Clini cal-Fellowship.htm $=$. Missing or empty |title $=$ (help) "Professional Profile of the Speech and Language Therapist"

"Roles and Responsibilities of Speech-Language

Pathologists in Schools".

Hurlock, Elizabeth B., (1991). Perkembangan Anak Jilid 1. Jakarta : PT. Erlangga.

Izzaty, Rita Eka. (2005). Mengenali Permasalahan Perkembangan Anak Usia Dini. Jakarta : Depdiknas.

Kusumo Putro, Hidiarto.(1992). Afasia Gangguan Berbahasa. Jakarta : Fakultas Kedokteran UI.

Laura M Justice, Laura. Dkk. Language, Speech \& Hearing Services in Schools (Online). Washington: Apr 1, 2010. Vol. 41, Iss. 2; pg. 161, 18 pgs.

Lyle V. Jones and Joseph M. Wepman. Dimensions of Language Performance in Aphasia Author Notes Journal of Speech, Language, and Hearing Research, September 1961, Vol. 4, 220-232. doi:10.1044/jshr.0403.220

Mabel L. Rice, dkk. An overview of autism, Down syndrome, fragile $X$, specific language impairment, and Williams syndrome Language symptoms of developmental language disorders: Applied Psycholinguistics 26 (2005), 727 Printed in the United States of America DOI:
10.1017.S0142716405050034

University of Kansas.

Mary Beth Schmitt, Laura M. Justice, and Ann O'Connell Author Affiliations \& Notes Vocabulary Gain Among Children With Language Disorders: Contributions of Children's Behavior Regulation and Emotionally Supportive EnvironmentsAmerican Journal of Speech-Language Pathology, August 2014, Vol. 23, 373-384. doi:10.1044/2014_AJSLP-120148 History: Received November 18, 2012; Revised June 4, 2013; Accepted November 29, 2013

Mashburn, Andrew.dkk. Language, Speech \& Hearing Services in Schools (Online). Washington: Jan 1, 2010. Vol. 41, Iss. 1; pg. 61, 9 pgs. Mihaela Frățilă, Emil Urtilă, Maria Ștefănescu (Oct 2011). "Speech therapy - criteria for determining the time of the surgical operation in surgery of labio-palato-velars cleft". Rev. chir. oro-maxilo-fac. implantol. (in Romanian) 2 (2): 21-23. ISSN 2069-3850. 33. Retrieved 2012-0606.(webpage has a translation button)

Musfiroh, Takdiroatun. (2009). Menumbuhkembangkan BacaTulis Anak Usia Dini. Jakarta : PT Gramedia Widiasarana Indonesia.

Musthafa, Bachrudin. (2008). Dari Literasi Dini ke Literasi Teknologi. Bandung : CREST. (2014). Literasi

Dini dan Literasi Remaja : Teori, Konsep dan Praktik. Bandung : CREST. 
Paciaroni M, Agnelli G, Caso V, Bogousslavsky J (eds): Manifestations of Stroke.Aphasia and Other Language Disorders. Front Neurol Neurosci. Basel, Karger, 2012, vol 30, pp 4145Sagi, I. \& Yechiam, E. (2008). Amusing

Pamela A. Hadley and Kathleen M. Walsh. Toy Talk: Simple Strategies to Create Richer Grammatical Input, Author Affiliations \& Notes Language, Speech, and Hearing Services in Schools, July 2014, Vol. 45, 159-172.

doi:10.1044/2014_LSHSS-13-

0055. History: Received July 28, 2013; Revised January 16, 2014; Accepted March 20, 2014

Pollens R (October 2004). "Role of the speech-language pathologist in palliative hospice care". J Palliat Med7 (5): 694702.

doi:10.1089/jpm.2004.7.694.

Roger J. Robinson. Causes and Associations of Severe and Persistent Specific Speech and Language Disolders in Children. Article first published online: 12 NOV 2008 DOI: $10.1111 / \mathrm{j} .1469-$

8749.1991.tb14811.x Issue .

Santrock, John W. (2007). Perkembangan Anak Jilid 1 dan 2. Jakarta : Penerbit Erlangga.

Sherwood, Mellanie. dkk.,2008.

Retrospective Parent Report of Early Vocal Behaviours in Children with Suspected Childhood Apraxia of Speech (sCAS).www.prequest.com/pq dweb.
Sternberg, Robert J. (2008). Psikologi Kognitif Edisi Keempat. Yogyakarta : Pustaka pelajar.

Stothard, S. E., Snowling, M. J., Bishop, D. V. M., Chipchase, B. B., \& Kaplan, C. A. (1998). Language-impaired preschoolers: A follow-up into adolescence. Journal of Speech Language and Hearing Research, 41, pp. 407-418.

Sukmadinata, Nana Syaodih. (2005). Landasan Psikologi Proses Pendidikan. Bandung : PT Remaja Rosdakarya.

Tarigan, Henri G. (2009). Strategi Pengajaran dan Pembelajaran Bahasa. Bandung : Angkasa.

(2013). Membaca. Bandung Penerbit Angkasa.

Tomblin, J.B., Records, N.L., Buckwalter, P., Zhang, X., Smith, E. \& Brien, O.M. (1997). Prevalence of specific language impairment in kindergarten children. Journal of Speech, Language and Hearing Research, 40, 12451260.

Van Agt, Heleen. (2011). Language Disorders in Children: Impact and the Effect of Screening Taalstoornisssen bij Kinderen:Impact en de Effecten van Screening. Den Haag

(2013). Membaca. Bandung : Penerbit Angkasa.

Webster, R.I., Shevell, M. I. (2004). Neurobiology of Specific Language Impairment. Journal of Child Neurology, 19(7): 471481.

Y L Shong, Sussana. Dkk. New York: 2009. Vol. 170, Iss. 3; pg. 193, 4 pgs.

Zubaidah, Enny. Draft Buku Pengembangan Bahasa AUD. 
Didaktik : J urnal Pendidikan Guru Sekolah Dasar, ISSN : 2477-5673

Sekolah Tinggi dan IImu Pendidikan Subang

Volume I Nomor 1, Desember 2015

Yogyakarta: Fakultas IImu

Pendidikan UNY.

"2005 SLP Standards". 2005

Standards and Implementation

Procedures for the Certificate

of Clinical Competence in

Speech-Language Pathology. 